\title{
Role of surgical resection in the treatment of hypothalamic hamartomas causing precocious puberty
}

\section{Report of six cases}

\section{Laura Stewart, M.D., F.R.C.P.(C), Paul Steinbok, M.B.B.S., F.R.C.S.(C), and Jorge Daaboul, M.D., F.A.A.P.}

Division of Endocrinology, Department of Paediatrics and Division of Neurosurgery, Section of Surgery of British Columbia's Children's Hospital, Vancouver, British Columbia, Canada; and Department of Paediatrics and Division of Neurosurgery, Department of Surgery of the University of British Columbia, Vancouver, British Columbia, Canada

Hypothalamic hamartomas (HHs) are benign tumors that are often associated with central precocious puberty. Resection of HHs has been recommended as a treatment option for selected cases of pedunculated lesions, especially in young children. The role of surgery has to be evaluated in the light of the availability of effective medical treatment with gonadotropin-releasing hormone analogs (GnRHas). The authors report the long-term results of total resection of HHs in two children with central precocious puberty and compare it with medical management in four children.

The two surgically treated patients underwent total resection of pedunculated HHs at 1.75 (Case 1) and 3.25 years (Case 2) and have received follow-up care for 9 and 8 years, respectively. There were no postoperative complications and computerized tomography scanning confirmed complete tumor removal in both patients. Both patients subsequently experienced some regression of secondary sexual characteristics. The response of luteinizing hormone to GnRH became prepubertal in one patient and was diminished in the other. However, the growth velocity remained elevated ( $\mathrm{gt} 7 \mathrm{~cm} / \mathrm{year}$ ), bone age remained advanced ( $\mathrm{gt}+2$ standard deviations) 5 years after surgery, decreasing adult height prediction. In one child, GnRHa therapy was initiated 7 years postsurgery.

Four children were treated solely with GnRH agonists and have received follow-up care for 2.3, 6, 9, and 9 years, respectively. These patients have had a complete regression of endocrinological abnormalities, including a normalization of growth velocity and reduction in the rate of skeletal maturation. No side effects were noted with decapeptyl treatment, and one child developed sterile abscesses while receiving Lupron-Depot.

The proven efficacy of GnRHa in suppressing puberty and reducing bone age advancement leads the authors to advise against surgery as the initial management of central precocious puberty caused by HHs. Key Words * hamartoma * precocious puberty * hypothalamus * endocrinology * surgery 
Hypothalamic hamartomas (HHs) have been recognized as a cause of central precocious puberty and with the advent of computerized tomography (CT) and magnetic resonance (MR) studies, they have been diagnosed more frequently.[1] Effective medical therapy for central precocious puberty became available in the past decade with the introduction of gonadotropin-releasing hormone analogs (GnRHas) and particularly the newer long-acting preparations.[15] Concurrent with these developments in medical therapy, advances in neuroradiology and microneurosurgical techniques have made the resection of HHs a viable and relatively safe option to consider in the treatment of precocious puberty when such an associated hypothalamic lesion is present.[1]

In this report, the current role of surgical resection of hypothalamic lesions for treatment of precocious puberty caused by HHs is reviewed in light of our long-term experience with two children treated with surgical resection and a somewhat shorter experience with four children treated only with GnRHas.

\section{PATIENTS AND MATERIALS}

Six patients (five girls and one boy) who presented with sexual precocity and $\mathrm{HH}$ received treatment and follow-up care at the endocrine unit of the British Columbia's Children's Hospital (BCCH). Their medical records were reviewed to obtain information about medical and surgical treatments, clinical and endocrinological assessments, and neuroradiological investigations.

Patients with central precocious puberty were enrolled in a study protocol to assess the efficacy of D-6-Trp (decapeptyl). They underwent clinical and biochemical assessment at baseline, 3 weeks after the first dose of decapeptyl, then every 3 months for 1 year, and every 6 months thereafter until puberty and growth were completed following discontinuation of the drug. Their workups included a history and physical examination to assess pubertal status and possible side effects of the medication. During each visit at the treatment phase, a 1-hour GnRH stimulation test was performed just prior to injection of the GnRH agonist. Bone age was assessed at baseline and every 6 months thereafter by using Greulich and Pyle's standards.[9] A cranial MR image or CT scan was obtained at baseline.

The surgically treated patients underwent clinical and biochemical assessment at baseline, 1 week postoperatively, 3 months postoperatively, and every 6 months thereafter for 2 years. These assessments included a history, physical examination, and GnRH stimulation test. The bone age was checked annually. The children received annual follow-up reviews consisting of clinical assessments; evaluation of baseline estradiol $\left(\mathrm{E}_{2}\right)$, luteinizing hormone $(\mathrm{LH})$, and follicle-stimulating hormone (FSH) levels; and bone age assessments.

The children underwent a standard GnRH stimulus test ( $0.1 \mathrm{mg}$ administered intravenously). The LH and FSH levels were assessed using Delfia kits. The $\mathrm{E}_{2}$ level was assessed using the Pantex kit (an extraction radioimmunoassay method). Their bone age was assessed according to the method of Greulich and Pyle.[9]

\section{RESULTS}

\section{Treatment Options}

In two patients, total surgical resection of the $\mathrm{HH}$ was accomplished via a pterional approach, with no complications. In one patient (Case 1), this was the initial treatment for precocious puberty, whereas in the second patient (Case 2), surgery was performed after she exhibited an inadequate response to 
treatment with the GnRHa, D-6-ser-Des-Gly $\mathrm{NH}_{2}$ (Buserelin).

The GnRHa treatment was used as the first approach in five patients. Two patients were initially treated with Buserelin, one for 25 months prior to resection of the hamartoma (Case 2), and the other for 4.25 years (Case 3, at which time her medication was switched to decapeptyl (3.75 mg administered intramuscularly every 3 weeks). Two patients were treated with decapeptyl only (Cases 4 and 5). One was treated with Lupron and D6-leu-Des-Gly- $\mathrm{NH}_{2}$ (Lupron-Depot) for 5.5 years, then her medication was switched to decapeptyl (Case 6). The dosage of decapeptyl was $120 \mu \mathrm{g} / \mathrm{kg}$ given intramuscularly every 3 weeks. (The medication was provided by Ferring, Willowdale, ON). One patient was treated with decapeptyl after a recurrence of puberty postsurgery (Case 2).

\section{Neuroradiological Studies}

Postoperative CT scans demonstrated pedunculated HH in the two children in whom resection had been performed and in two others who had received medical treatment. The remaining children were found to have sessile HHs.

\section{Endocrinological Assessments}

After surgical resection of the HHs in two patients, the LH and FSH responses to GnRH stimulation improved, but the responses become prepubertal in only one child (Case 2). In both surgically treated children, there was rapid progression of puberty, with exaggerated gonadotropin responses to GnRH testing and rapid skeletal maturation at the chronological ages of 8 and 9 years, respectively. Surgical resection of the hamartoma resulted in a decrease in the excessive growth velocity (GV), but not to a prepubertal rate.

Medical treatment with Buserelin and Lupron effected only partial reversal of the abnormalities of gonadotropins and growth, whereas decapeptyl treatment resulted in complete reversal of biochemical disturbances to prepubertal status, with normalization of the growth rate and bone age, such that the adult height prediction became appropriate for the child's genetic potential.

\section{Clinical Assessment}

Surgical treatment resulted in partial regression of secondary sexual characteristics in both patients, but rapid pubertal development occurred concurrent with the biochemical changes of puberty at 8 and 9 years of age, respectively. Their GVs remained pubertal $(6-8 \mathrm{~cm} /$ year) with their bone ages advancing 1 to 1.5 years annually until the patients reached 8 and 9 years of age, respectively, at which time the bone age advanced 2 to 3 years annually. In the two children treated initially with Buserelin and the child treated with Lupron, there was incomplete regression of secondary sexual characteristics. However, when therapy was changed to decapeptyl, there was clinical regression of secondary sexual characteristics, prepubertal GVs, and a slowed rate of skeletal maturation. Both children treated initially with decapeptyl showed complete regression of pubertal changes. Their GVs $(3.7-6 \mathrm{~cm} /$ year $)$ were prepubertal except for the 14-month-old boy, who had a growth velocity of $11 \mathrm{~cm} / y e a r$, which was appropriate for his chronological age. The ratio of the change in bone age to change in chronological age was less than 0.5. These children tend to have an elevated body mass index (BMI) for bone age at the time of diagnosis and this persists regardless of whether patients receive medical or surgical treatment (Table 1). 


\section{TABLE 1}

Effects of Treatment on Puberital Status, Height, and Bone age in Patents with Central Priecocious PUEERTY AND HYPOTHALAMK HAMARTOMAS

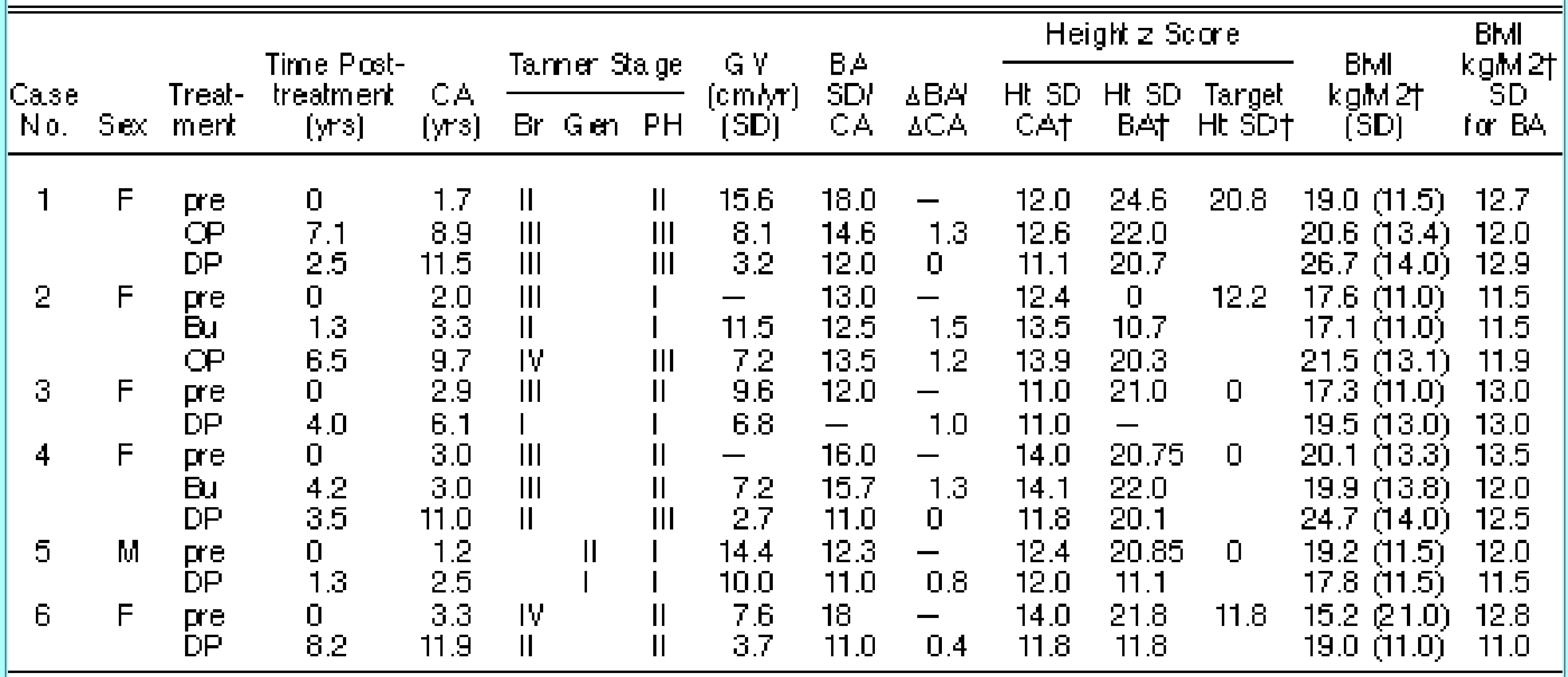

" $\mathrm{BA}=$ bone age; $\mathrm{BA} \mathrm{SD} / \mathrm{CA}=$ bone age $\mathrm{SD}$ for chronological age; $\mathrm{ABA} / \mathrm{ACA}$ = change in bone age per change in chronological age; DP = decapepty; gen = genitalia (male); GV = growth velocity, Ht SD/BA = height SD per bone age; $\mathrm{Ht} \mathrm{SD} / \mathrm{CH}=$ height $\mathrm{SD}$ for chronological age; $\mathrm{PH}=$ putic hair; target ht $\mathrm{SD}=$ mid-parental height $\mathrm{SD} ; \mathrm{SD}=\mathrm{stan}-$ dard de viation.

† A $z$ score of $0=50$ th peroentile for height. In this context SD means height standard deviation.

\section{CASE REPORTS}

\section{Case 1}

History. This girl (whose case has been reported previously in part by Steinbok and Tze[22]) presented at the age of 17 months with precocious puberty (Table 1). A pubertal response was seen on GnRH testing (Table 2). A cranial CT scan and cysternogram demonstrated an HH (Fig. 1 left). 
TABLE 2

RESULTS OF GNRH STMULATION TESTS IN SIX CHLDREN WITH PRECOCIOUS PUBERTY CAUSED BV HHS ${ }^{\star}$

\begin{tabular}{|c|c|c|c|c|c|c|c|c|c|c|c|}
\hline \multirow{2}{*}{$\begin{array}{l}\text { Case } \\
\text { No. }\end{array}$} & \multicolumn{3}{|c|}{$\begin{array}{l}\text { Wean Peak } \\
\text { LH (IUPL) }\end{array}$} & \multicolumn{3}{|c|}{$\begin{array}{c}\text { Mean Peak } \\
\text { FSH (IUIL) }\end{array}$} & \multicolumn{3}{|c|}{$\begin{array}{l}\text { Mean } E_{2} \\
\text { (pmollt) }\end{array}$} & \multicolumn{2}{|c|}{$\begin{array}{c}\text { Mean Tes- } \\
\text { tosterone } \\
\text { (nmol' L) }\end{array}$} \\
\hline & Pre & DP & OP & Pre & DP & OP & Pre & DP & $\alpha P$ & Pre & DP \\
\hline 1 & 97 & 0.4 & 22 & 45 & 3.6 & 11.9 & 83 & $\times 40$ & $\ddagger$ & - & - \\
\hline 2 & 67 & - & $\S$ & 22 & - & $\S$ & 51.3 & - & $i$ & - & - \\
\hline 3 & 74 & 0.4 & - & 18 & 0.7 & - & 275 & $\times 40$ & - & - & - \\
\hline 4 & 46 & 0.8 & - & 60 & 0.8 & - & 242 & $\times 40$ & - & - & - \\
\hline 5 & 21 & 0.9 & - & 1 & 0.2 & - & - & - & - & 1.0 & $\times 0.2$ \\
\hline 6 & 62.3 & 0.1 & - & 15.0 & 0.5 & - & 204 & $\times 40$ & - & - & - \\
\hline \multicolumn{12}{|c|}{ 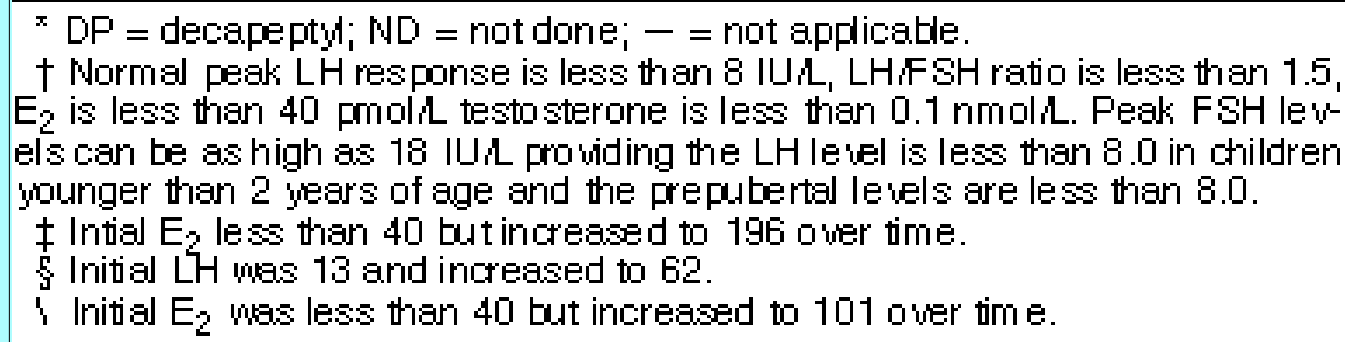 } \\
\hline
\end{tabular}

Operation. The HH was completely removed surgically via a pterional approach when the patient was 21 months old, and the diagnosis was confirmed on histopathological examination. The patient exhibited no neurological sequelae. Her menses ceased, but there was no change in secondary sexual characteristics until 7.6 years of age, when progression occurred. Her GnRH stimulation test remained pubertal for 3 years. We suggested medical therapy, but the parents refused it at that time.

Follow-Up Review. At 8 years of age her menses recurred and her GnRH test was pubertal. A repeated CT scan showed no evidence of the tumor (Fig. 1 center), and more recently MR imaging has confirmed that there is no residual or recurrent $\mathrm{HH}$ (Fig. 1 right).
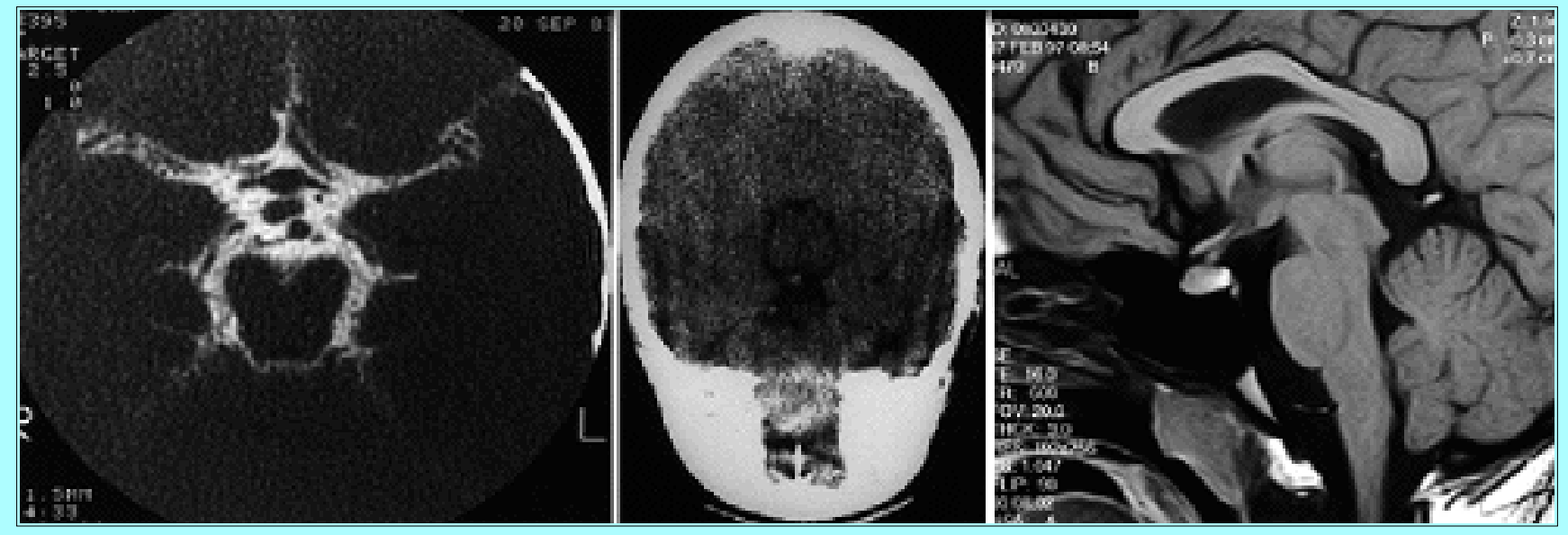

Fig. 1. Case 1. Left: Cisternogram showing the hamartoma prior to surgery. Center: Axial CT scan obtained 6.5 years postoperatively showing no evidence of residual hamartoma. Right: Sagittal MR image obtained 9 years postoperatively showing no evidence of tumor recurrence.

Medical Treatment. The patient was started on a course of decapeptyl (120 $\mu \mathrm{g} / \mathrm{kg}$ every 3 weeks) at 9 years of age and was treated for 3 years. Her secondary sexual characteristics showed some regression and menses ceased. While she was receiving treatment, there was biochemical suppression of puberty 
(Table 2). Her bone age did not advance after starting the course of decapeptyl, her GV was 2.73 $\mathrm{cm} / y e a r$, and her height improved, such that it became appropriate for her genetic potential (Table 1).

Outcome. Decapeptyl was discontinued when the patient was 12 years of age. After treatment had been discontinued for 12 months, her menses resumed and are now regular.

\section{Case 2}

History. This 14-month-old girl presented with breast and pubic hair development at 14 months of age. She was premenarchal, her pubertal stage was III for breast and I for pubic hair development, and her bone age was 3 years. The GnRH stimulation test was pubertal (Table 2).

Medical Treatment. The patient was treated with Buserelin $(20 \mu \mathrm{g} / \mathrm{kg} / \mathrm{day})$. There was some regression of breast development, and her GV slowed 15 months after initiation of therapy. The GnRH stimulation test remained pubertal (Table 2).

Operation. A CT scan demonstrated showed a pedunculated $\mathrm{HH}$, and complete surgical resection was accomplished via a pterional approach at age 3.25 years with no neurological sequelae. The tissue was typical of an $\mathrm{HH}$, with positive staining for $\mathrm{GnRH}$. There was no clinical change in her pubertal status until 5 years of age, when there was evidence of breast regression to Tanner Stage II. The gonadotropin response to GnRH testing was suppressed 4 months after surgery, with LH and FSH levels of less than 1 IU/L. The FSH response gradually climbed over the next year to a level of $62 \mathrm{IU} / \mathrm{L}$ but the $\mathrm{LH}$ remained at less than $1 \mathrm{IU} / \mathrm{L}$. Her GV (6.3 cm/year) was appropriate for her chronological age until she reached 7 years of age. The rate of skeletal maturation was equal to her change in chronological age.

Outcome. Puberty resumed between the ages of 7 and 8 years, with rapid progression to Tanner stage IV breast development and Tanner II pubic hair development at the ages of 9.5 years. Her GV increased simultaneously with rapid skeletal maturation; her bone age was 13 years. Her predicted height is below that of her genetic potential but acceptable; therefore medical intervention was not initiated. The GnRH test was pubertal (Table 2).

\section{Case 3}

History. This girl presented at the age of 23 months with breast development starting at 17 months of age, pubic hair at 22 months, and menses at 22 months (Table 1).

Treatment and Outcome. She was started on a course of decapeptyl (120 $\mu \mathrm{g} / \mathrm{kg}$ every 3 weeks) at 25 months of age and continues to receive treatment. She now has been treated for 7 years with no side effects. Her pubertal changes regressed completely after 9 months of therapy. She has maintained a normal GV (height following the 75th percentile), and her bone and chronological ages are equivalent. Her predicted adult height is appropriate for her genetic potential (Table 1). While she has been receiving hormone therapy, all her GnRH tests have been prepubertal (Table 2).

\section{Case 4}

History. This girl presented at the age of 3 years with breast and pubic hair development. She had a pubertal GnRH test (Table 2), and her bone age was 5.75 years. A CT scan showed a pedunculated HH. She was initially treated with Buserelin at a dosage of $1000 \mu \mathrm{g}$ once a day ( $40 \mu \mathrm{g} / \mathrm{kg} /$ day) and continued treatment with that analog until the age of 7.4 years. Her breast development regressed but did not entirely resolve. Her linear GV remained high at $6.8 \mathrm{~cm} /$ year and her bone age continued to advance at a 
rate equivalent to her chronological age.

Treatment. When the patient was 7.4 years of age her medicine was switched to decapeptyl $(120 \mu \mathrm{g} / \mathrm{kg}$ every 3 weeks) to obtain better pubertal suppression. She received this medication for 4 years. While receiving decapeptyl her $\mathrm{GV}$ decelerated to $2.7 \mathrm{~cm} /$ year, and her height now is in the normal range. Her gonadotropin and $\mathrm{E}_{2}$ levels are appropriately suppressed (Table 2). Her bone age (age 12 years) did not change during therapy and her predicted height was appropriate for her genetic potential when decapeptyl was discontinued (Table 1).

Outcome. The patient discontinued therapy at 11.5 years of age, and she has not received drug treatment for 1.5 years. She is at Tanner Stage IV for breast and public hair development. Her menses started 1.3 years after discontinuation of therapy and are regular. She has grown $6.7 \mathrm{~cm}$ and is $160 \mathrm{~cm}$ tall, with a bone age of 15 years.

\section{Case 5}

History. This boy presented at the age of 13 months with an 8-month history of an enlarged phallus and a 4-month history of pubic hair development and increased scrotal pigmentation (Table 1). Testing for GnRH was pubertal (Table 2), the patient's bone age was 2 years, and a cranial CT scan revealed a sessile $\mathrm{HH}$.

Treatment and Outcome. Treatment with decapeptyl (120 $\mu \mathrm{g} / \mathrm{kg}$ every 3 weeks) was initiated when the patient was 15 months of age, and he has been receiving treatment for 1.5 years. Within 2 months of the initial treatment, biochemical suppression was noted (Table 2). His secondary sexual characteristics regressed to prepubertal levels within 5 months. His GV of $11.5 \mathrm{~cm} /$ year is normal for his chronological age. His bone age is 4 (+1 standard deviation) at a chronological age of 3.7 years, and his predicted adult height is appropriate for his genetic potential (Table 1). According to his history, he is acting like a normal 4-year-old and is not aggressive.

\section{Case 6}

History. This girl presented at 2.8 years of age with breast development that had started at 2 years of age, followed by public hair development (Table 1). An MR image showed a sessile HH. Her GnRH stimulation test was pubertal (Table 2), her bone age was 6.8 years, and her GV was $7.6 \mathrm{~cm} /$ year.

Treatment and Outcome. She was treated with Lupron, then Lupron-Depot ( $7.5 \mathrm{mg}$ every 4 weeks) from 3 to 8.5 years of age inclusive, with regression of pubertal changes. Her GV was $6.7 \mathrm{~cm} /$ year, and she displayed incomplete biochemical suppression on GnRH testing (Table 2). She experienced recurrent sterile abscesses while receiving Lupron-Depot. Her medication was switched to decapeptyl $(120 \mu \mathrm{g} / \mathrm{kg}$ every 3 weeks) at 8.5 years of age, with complete suppression of puberty resulting (Table 1). She has had no abscesses while receiving decapeptyl treatment.

\section{DISCUSSION}

\section{Surgical Resection}

In 1967, Northfield and Russell[17] were the first to describe the surgical resection of HHs for treatment of precocious puberty, and since then there have been a number of cases reported in which excision of the hamartoma has been achieved safely and has resulted in regression of this condition. $[1,2,4,12,14]$ In 
1990, Starceski, et al.,[21] reviewed the literature relating to HHs and precocious puberty and identified 33 surgically treated cases reported since 1958. In 27 of these cases, there was incomplete resection of the hamartoma, and clinical and hormonal improvement occurred in only one; after "total" resection, three of six demonstrated regression of puberty. Recent reports have been more positive, with Boyko, et al.,[4] reporting on three patients, and Albright and Lee[1] reporting on five in whom total resection of an $\mathrm{HH}$ reversed the endocrinological features of precocious puberty. Because total resection of the hamartoma appears to be necessary for a good endocrinological result, effective surgical treatment is limited to those lesions that are pedunculated and thus more amenable to total removal.

Our experience with surgical resection of HHs in two patients confirms previous findings that with current microneurosurgical techniques it is possible to achieve a total resection of a pedunculated lesion with minimal morbidity. Three of five children in the series reported by Albright and Lee[1] exhibited transient ocular motor paresis and one child required surgery of the eye muscles, but there was no other morbidity related to the surgical procedure performed via a subtemporal approach. Our two surgically treated patients underwent operation via a pterional approach, and there was no morbidity related to the surgical resection. The initial impression of the response to surgical resection in both of our patients was that the resection had been successful in curing the precocious puberty. However, with prolonged follow-up review, it became clear that the reversal of puberty had not been complete, and permanent cure of the precocious puberty had not been achieved. Gonadotropin levels were reduced postoperatively but not necessarily to prepubertal levels, and with time there was deterioration in this effect. Moreover, although the GV decreased in both patients compared with their preoperative rates, it remained abnormally high. Additionally, the rate of skeletal maturation was inappropriately rapid, such that the predicted adult height was diminished. These findings are at variance with the experience of Albright and Lee,[1] who reported complete reversal of all endocrine abnormalities in five patients undergoing total resection of an $\mathrm{HH}$, including one patient who remained normal until resumption of puberty 10 years postsurgery, at 10.5 years of age. The completeness of the reversal of endocrinological abnormalities in Albright and Lee's series is difficult to assess, because full details of the endocrine assessments have not been given.

It has been postulated that central precocious puberty secondary to $\mathrm{HH}$ is caused by an interruption of normal inhibitory pathways that results in the autonomous pulse release of $\mathrm{GnRH}$ from the $\mathrm{HH}$. One might therefore expect total resection of the $\mathrm{HH}$ to be curative. However, there may also be interruption of the inhibitory pathways to the pituitary because of the location of the $\mathrm{HH}$ and/or the surgical intervention area, and this may result in pubertal progression even if the lesion is completely removed.

\section{Medical Therapy}

Therapy using a GnRH agonist is the accepted form of treatment for idiopathic central precocious puberty and has been shown to be effective both in the short term[3] and in the long term. [15] Treatment with the newer sustained-release preparations, Lupron-Depot $[6,16]$ and decapeptyl,[18,20] has resulted in normalization of $\mathrm{GV}$, regression of secondary sexual characteristics, a slowed rate of skeletal maturation, and the attainment of adult height appropriate to genetic potential.[5,13]

Our experience indicates that GnRH agonist therapy is also effective in central precocious puberty secondary to $\mathrm{HH}$. The five children who received an adequate dose of $\mathrm{GnRH}$ agonist, four as their sole therapy and one who had resumption of puberty postsurgery, exhibited an excellent response. The gonadotropin and sex steroid levels were suppressed (LH lt 1 IU/L, FSH lt 5 IU/L, testosterone lt 0.3 
$\mathrm{nmol} / \mathrm{L}, \mathrm{E}_{2}$ lt $\left.40 \mathrm{pmol} / \mathrm{L}\right) 3$ weeks after patients began their course of medication and remained suppressed for the duration of treatment. There was clinical regression of puberty, GV normalization for their bone age, a rate of skeletal maturation that was slower than the change in chronological age, and predicted heights that were appropriate for their genetic potentials. The moodiness and pubertal behavior, flirtatiousness in the girls and aggressiveness in the boys, resolved within 6 to 12 months.

We saw a difference in clinical response to GnRH agonists. All children treated with decapeptyl demonstrated rapid clinical and biochemical regression of puberty. The two children (Cases 2 and 4) treated with the short-acting agonist Buserelin, and the child (Case 6) treated with Lupron and Lupron-Depot, had evidence of inadequate pubertal suppression. These children also remained moody, which was not unexpected, because reversal of pubertal behavior has only been seen when there is complete gonadotropin suppression. Such incomplete gonadotropin suppression may explain the findings of Albright and Lee[1] that Lupron-Depot was ineffective in reversing aggression in their patients.

Potential concerns about medical management of central precocious puberty secondary to $\mathrm{HH}$ include side effects, the possibility of growth of the hamartoma, and cost of the drugs. There have been reports of hives and sterile abscesses in patients treated with Lupron-Depot, and in some cases, therapy has had to be discontinued.[16] These reactions are rarely seen in patients treated with decapeptyl, and no other complications have been reported. Except for one girl who developed sterile abscesses while receiving treatment with Lupron-Depot, there were no side effects in our patients treated with GnRH agonists. In our study, decapeptyl has been discontinued in two children (Cases 1 and 4), with resumption of puberty and menses in both cases, in keeping with the experience of others.[10,15] The question of growth of the $\mathrm{HH}$ while the patient receives medical treatment is hypothetical, and has been examined by Mahachoklertwattana, et al.,[15] who found no changes in the size of the HHs after prolonged treatment with GnRH agonists. Expense is also a concern, because GnRH agonists cost approximately \$200 (U.S.) per injection, and injections are typically given every 3 weeks.

\section{CONCLUSIONS}

Total resection of an $\mathrm{HH}$ is the only surgical procedure that has a significant chance of reversing precocious puberty, and for pedunculated hamartomas such a total removal can be accomplished safely. Nonetheless, the operation does entail a definite risk. Furthermore, our experience indicates that even after what is thought to be a complete surgical resection, reversal of precocious puberty may be incomplete, and with time the endocrine abnormalities may recur. Effective, safe medical treatment with a long-acting GnRH agonist is available and has been uniformly successful. There are significant costs associated with medical treatment and a need for repeated injections over many years, but in view of the risks of a major craniotomy and the uncertain outcome postsurgery, we recommend that the initial management for a child with precocious puberty secondary to $\mathrm{HH}$, even when it is pedunculated, should be medical treatment with a long-acting GnRH agonist.

\section{References}

1. Albright AL, Lee PA: Neurosurgical treatment of hypothalamic hamartomas causing precocious puberty. J Neurosurg 78:77-82, 1993

2. Alvarez-Garijo JA, Albiach VJ, Vila MM, et al: Precocious puberty and hypothalamic hamartoma with total recovery after surgical treatment. Case report. J Neurosurg 58:583-585, 1983 
3. Boepple PA, Mansfield MJ, Wierman ME, et al: Use of a potent, long acting agonist of gonadotropin-releasing hormone in the treatment of precocious puberty. Endocrin Rev 7:24-33, 1986

4. Boyko OB, Curnes JT, Oakes WJ, et al: Hamartomas of the tuber cinereum: CT, MR, and pathologic findings. AJNR 12:309-314, 1991

5. Brauner R, Adan L, Malandry F, et al: Adult height in girls with idiopathic true precocious puberty. J Clin Endocrinol Metab 79:415-420, 1994

6. Clemons RD, Kappy MS, Stuart TE, et al: Long-term effectiveness of depot gonadotropin-releasing hormone analogue in the treatment of children with central precocious puberty. Am J Dis Child 147:653-657, 1993

7. Conn PM, Crowley WF Jr: Gonadotropin-releasing hormone and its analogues. N Engl J Med 324:93-103, 1991

8. Culler FL, James HE, Simon ML, et al: Identification of gonadotropin-releasing hormone in neurons of a hypothalamic hamartoma in a boy with precocious puberty. Neurosurgery 17:408-412, 1985

9. Greulich, W, Pyle I: Radiological Atlas of Skeletal Development of the Hand and Wrist. Stanford: Stanford University Press, 1959

10. Jay N, Mansfield MJ, Blizzard RM, et al: Ovulation and menstrual function of adolescent girls with central precocious puberty after therapy with gonadotropin-releasing hormone agonists. J Clin Endocrinol Metab 75:890-894, 1992

11. Judge DM, Kulin HE, Page R, et al: Hypothalamic hamartoma: a source of luteinizing-hormone-releasing factor in precocious puberty. N Engl J Med 296:7-10, 1977

12. Kammer KS, Perlman K, Humphreys RP, et al: Clinical and surgical aspects of hypothalamic hamartoma associated with precocious puberty in a 15-month-old boy. Childs Brain 7:150-157, 1980

13. Kreiter M, Burstein S, Rosenfield RL, et al: Preserving adult height potential in girls with idiopathic true precocious puberty. J Pediatr 117:364-370, 1990

14. Kyuma Y, Kato E, Sekido K, et al: Hypothalamic hamartoma successfully treated by operation. Case report. J Neurosurg 62:288-290, 1985

15. Mahachoklertwattana P, Kaplan SL, Grumbach MM: The luteinizing hormone-releasing hormone-secreting hypothalamic hamartoma is a congenital malformation: natural history. J Clin Endocrinol Metab 77:118-124, 1993

16. Neely EK, Hintz RL, Parker B, et al: Two-year results of treatment with depot leuprolide acetate for central precocious puberty. J Pediatr 121:634-640, 1992

17. Northfield DWC, Russell DS: Pubertas praecox due to hypothalamic hamartoma: report of two cases surviving surgical removal of the tumour. J Neurol Neurosurg Psychiatry 30:166-173, 1967

18. Oostdiuk LW, Drop SLS, Odink RJH, et al: Long-term results with a slow-release gonadotrophin-releasing hormone agonist in central precocious puberty. Dutch-erman Precocious Puberty Study Group. Acta Paediatr Scand (Suppl) 372:39-45, 1991 
19. Pescovitz OH, Comite F, Hench K, et al: The NIH experience with precocious puberty: diagnostic subgroups and response to short-term luteinizing hormone releasing hormone analogue therapy. J Pediatr 108:47-54, 1986

20. Roger M, Chaussain JL, Berlier P, et al: Long term treatment of male and female precocious puberty by periodic administration of a long-acting preparation of d-trp 6 -luteinizing hormone-releasing hormone microcapsules. J Clin Endocrin Metab 62:670-677, 1986

21. Starceski PJ, Lee PA, Albright AL, et al: Hypothalamic hamartomas and sexual precocity. Evaluation of treatment options. Am J Dis Child 144:225-228, 1990

22. Steinbok P, Tze WJ: Treatment of precocious puberty by surgical removal of hypothalamic hamartoma: a case report, in Kageyam N (ed): Proceedings of the 1st International Symposium on Pediatric Neuro-Oncology. Tokyo: University of Nagoya Press, 1987, pp 188-192

Manuscript received May 24, 1996.

Accepted in final form August 1, 1997.

Address reprint requests to: Laura Stewart, M.D., Endocrine and Diabetes Clinic, British Columbia's Children's Hospital, 4480 Oak Street, Vancouver, British Columbia, V6H 3V4 Canada. 